\title{
Association of Metabolic and Genetic Factors With Cholesterol Esterification Rate in HDL Plasma and Atherogenic Index of Plasma in a 40 Years Old Slovak Population
}

\author{
K. RAŠLOVÁ ${ }^{1}$, M. DOBIÁŠOVÁ ${ }^{2}$, J. A. HUBÁČEK ${ }^{3,4}$, D. BENCOVÁ ${ }^{5}$, D. SIVÁKOVÁ ${ }^{5}$, \\ Z. DANKOVÁ ${ }^{5}$, J. FRANEKOVÁ ${ }^{6}$, A. JABOR ${ }^{6}$, J. GAŠPAROVIČ ${ }^{1}$, B. VOHNOUT ${ }^{1,7}$ \\ ${ }^{1}$ National Reference Centre for Familial Hyperlipoproteinemias, Slovak Medical University, \\ Bratislava, Slovakia, ${ }^{2}$ Institute of Physiology, Academy of Sciences of the Czech Republic, Prague, \\ Czech Republic, ${ }^{3}$ Institute for Clinical and Experimental Medicine, Prague, Czech Republic, ${ }^{4} \mathrm{Third}$ \\ Department of Medicine, First School of Medicine, Charles University, Prague, Czech Republic, \\ ${ }^{5}$ Department of Anthropology, Faculty of Sciences, Comenius University, Bratislava, Slovakia, \\ ${ }^{6}$ Department of Laboratory Methods, Institute for Clinical and Experimental Medicine, Prague, \\ Czech Republic, ${ }^{7}$ Department of Physiological and Clinical Nutrition, Faculty of Nursing and \\ Health Professional Studies, Slovak Medical University, Bratislava, Slovakia
}

Received August 27, 2010

Accepted March 1, 2011

On-line August 1, 2011

\section{Summary}

We assessed association between novel biomarkers of cardiovascular disease and conventional factors in 40 years old subjects (208 men and 266 women) from the general population

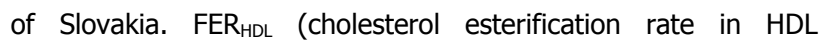
plasma), AIP - Atherogenic Index of Plasma [Log(TG/HDL-C)] as markers of lipoprotein particle size, and CILP2, FTO and MLXIPL polymorphisms, were examined in relation to biomarkers and conventional risk factors. Univariate analyses confirmed correlation between AIP, FER ${ }_{H D L}$ and the most of measured parameters. Relations between AIP and CILP2, FTO and MLXIPL were not significant. However, CILP2 was significantly related to $\mathrm{FER}_{\mathrm{HDL}}$ in both genders. In multivariate analysis BMI was the strongest correlate of AIP levels. In multivariate model variability of FER $R_{\text {HDL }}$ was best explained by AIP $\left(R^{2}=0.55\right)$ in both genders with still significant effect of CILP2 SNP in men. In a model where AIP was omitted, TG levels explained $43 \%$ of the FER HDL variability in men, while in women HDL-C was the major

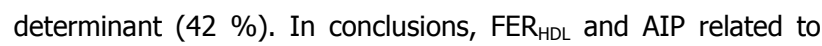
the known markers of cardiovascular risk provide means to express their subtle interactions by one number. Our novel finding of association between CILP2 polymorphism and FER $\mathrm{HDL}$ supports its role in lipid metabolism.

\section{Key words}

Fractional esterification rate of cholesterol $\left(\mathrm{FER}_{\mathrm{HDL}}\right) \cdot$ Atherogenic index of plasma (AIP) - Biomarkers of CVD • CILP2 • FTO • MLXIPL

\section{Corresponding author}

Katarína Rašlová, National Reference Centre for Familial Hyperlipoproteinemias, Slovak Medical University, Limbova 12, 83303 Bratislava, Slovakia. E-mail: katarina.raslova@yahoo.com

\section{Introduction}

Slovakia belongs to European countries with the highest cardiovascular mortality (Müller-Nordhorn et al. 2008). In 2003 we performed a large population study aimed to screen lipid disorders in subjects 40 years old in the year of the examination (Gašparovič et al. 2007). This age was chosen with respect to relatively low cardiovascular risk in that category and thus very effective possibility to diagnose, treat and prevent future cardiovascular event. In this study we assessed conventional risk factors (RF) of cardiovascular disease (CVD) such as plasma lipids, glycaemia and anthropometric parameters. This age homogenous 
population sample enabled to investigate how the novel biomarkers - fractional esterification rate of cholesterol in LDL/VLDL depleted plasma $\left(\mathrm{FER}_{\mathrm{HDL}}\right)$ and atherogenic index of plasma (AIP), markers of lipoprotein particle size, are related to the metabolic and genetic risk factors.

FER $_{\text {HDL }}$ has been shown to be the strongest predictor test of positive findings on coronary angiography (Frohlich and Dobiášová 2003) and one of best indicators of changes in the progression of coronary artery disease (CAD) after treatment with statins and antioxidants (Brown et al. 2001, Dobiášová et al. 2011). Its predictive potential consists in differently sized HDL cholesterol (HDL-C) subpopulations which regulate the rate of cholesterol esterification by lecithin cholesterol acyltransferase (LCAT). The size of lipoprotein particles is crucial not only for cholesteryl esters production but also for their destination (Dobiášová 2004). Differently sized lipoprotein particles play a protective (buoyant HDL-C and LDL-C particles) or an atherogenic role (small HDL-C and LDL-C particles) in cardiovascular disease (Austin et al. 1990, Drexel et al. 1992). Thus FER $_{\mathrm{HDL}}$ as a marker of lipoprotein particle size serves as a functional test of lipoprotein quality.

Logarithmically transformed ratio TG/HDL-C (Atherogenic Index of plasma - AIP) highly correlates

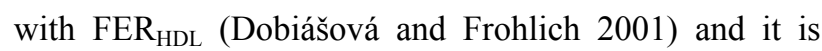
closely associated with particle size of HDL-C, LDL-C and VLDL (Dobiášová et al. 2005, 2011). Thus FER HDL and AIP may represent biomarkers of cardiovascular risk based on the lipoprotein particle size composition.

Recently, new identified loci and genes have been related to lipid concentrations and obesity. MLXIPL was primarily associated with triglyceride (TG) concentrations and CILP2 with LDL cholesterol (Kathiresan et al. 2008), variants in FTO (fat mass and obesity associated) gene with body mass index (BMI) (Scuteri et al. 2007, Hubáček et al. 2009).

The objective of the current study was to examine association of FER $\mathrm{HDL}_{\mathrm{H}}$ and AIP with metabolic factors and recently identified polymorphisms at novel lipid and obesity related loci (Kathiresan et al. 2008, Scuteri et al. 2007).

\section{Methods}

Screening of 40-year-old men and women was done in eight cities covering major part of Slovak regions in cooperation with MEDPED lipid clinics and
142 general practitioners (GPs) in 2003 (Gašparovič et al. 2007). For the current study we have randomly selected 474 subjects (208men, 266 women) out of the population study consisting of 2323 subjects. Fasting blood drawing, blood pressure and standard anthropometric measures were carried out in GPs' offices. The questionnaire covering personal and family history as well as smoking status filled by subjects was checked and confronted with medical records. The study was approved by the ethics committee of the Slovak Medical University. All study subjects agreed to participate by written informed consent.

Total cholesterol (TC), triglycerides (TG), HDL-C, apolipoprotein B (apoB), apolipoprotein AI (apoAI), alanine aminotransferase (ALT) and glucose levels were analyzed using enzymatic autoanalyzer methods. We considered ALT for the current study due to its suggestive role as a biomarker for the risk of metabolic and cardiovascular diseases (Goessling et al. 2008, Yilmaz 2010). LDL-C was calculated using the Friedewald formula. ApoB and apoAI were measured using automatic immunoturbidimetric assay for ApoA-I and ApoB (Abbott Architect system ci8200). Remaining plasma was stored in liquid nitrogen. DNA was isolated from peripheral blood leukocytes by the phenol extraction method and stored at $-80{ }^{\circ} \mathrm{C}$.

The assay of $\mathrm{FER}_{\mathrm{HDL}}$ has been previously described in detail (Dobiášová and Frohlich 1996). Briefly, apo B-containing lipoproteins were precipitated from EDTA plasma by phosphotungstic acid and $\mathrm{MgCl}_{2}$. To the supernatant which contains plasma with HDL only (HDL plasma), was added a filter paper disk containing a trace of 3-H cholesterol. After an overnight incubation at $4{ }^{\circ} \mathrm{C}$ the disk was removed, and the plasma with homogenously labeled HDL-C was incubated at $37^{\circ} \mathrm{C}$ for 30 min. Plasma lipids were extracted by ethanol, separated by thin layer chromatography. Spots of $\mathrm{CH}$ and CHE visualized by iodine were cut, transferred to vials with scintillation solution and measured. The fractional esterification rate was calculated from the ratio of radioactivity of free and esterified cholesterol. As this esterification only concerns the HDL-C, it was called fractional esterification rate in HDL-C $\left(\mathrm{FER}_{\mathrm{HDL}}\right)$ and its values were percentages of HDL-cholesterol esterified per hour.

AIP was calculated as the logarithmically transformed ratio of the molar concentration of TG to HDL-cholesterol (Dobiášová and Frohlich 2001).

DNA samples and results of genotypes of 
rs16996148 CILP2 (CILP), rs17817449 FTO (FTO) and rs3812316 MLXIPL (MLX) polymorphisms were available in 407 (183 males, 224 females), 439 (191 males, 248 females) and 431 (191 males, 240 females) subjects, respectively.

SNPs within the MLXIPL (Vráblik et al. 2008) and FTO (Hubáček et al. 2009) genes were determined as described elsewhere.

Rs16996148 variant near CILP/PBX4 genes was analyzed using PCR/RFLP. Briefly, oligonucleotides CILP-F 5' ctcttgtccactggecacatccec and CILP-R 5 ttctcccatgcctccaggecccaag were used. PCR product (135 bp) was cleaved by restriction enzyme Hin1II (Fermentas) and separated on $10 \%$ PAA gel (Day and Humphries 1994). The minor allele $\mathrm{T}$ is characterized by fragments of $82+53 \mathrm{bp}$, while an uncut fragment represents the major $\mathrm{G}$ allele.

Genotype frequencies (n, \%) were as follows: CILP - 345 (84.77\%), 57 (14\%), 5 (1.23\%), FTO - 135 (30.75\%), 203 (46.24\%), 101 (23.01\%), and MLX 335 $(77.72 \%), 88(20.42 \%), 8(1.86 \%)$ for genotypes 11,12 and 22 (with 1 representing the major allele and 2 representing the minor allele for each SNP). The frequencies of the alleles were determined by genotype count and compared with the values predicted on the basis of the assumption of Hardy-Weinberg equilibrium. The genotype distribution was in Hardy-Weinberg equilibrium for all 3 polymorphisms.

Risk factors were defined as follows: dyslipidemia if at least one of the TC>5.0 $\mathrm{mmol} / \mathrm{l}$, LDL-C $>3.0 \mathrm{mmol} / 1, \mathrm{HDL}-\mathrm{C}<1.0 \mathrm{mmol} / 1$ in men and HDL-C $<1.2 \mathrm{mmol} / 1$ in women, or TG $>1.7 \mathrm{mmol} / 1$, obesity if at least one of the BMI $>30 \mathrm{~kg} / \mathrm{m}^{2}$ or waist $>102 \mathrm{~cm}$ in men and waist $>88 \mathrm{~cm}$ in women, glucose $>6.0 \mathrm{mmol} /$, blood pressure (BP) if at least one of the systolic $\mathrm{BP}>140$ $\mathrm{mmHg}$ or diastolic BP $>90 \mathrm{mmHg}$ (De Backer et al. 2003), current smoking and positive family history of premature cardiovascular disease at age $<60$.

AIP risk categories were created according to published epidemiological data: Low risk $<0.11$, Intermediate 0.11-0.21 and High >0.21 (Dobiášová et al. 2008, www.biomed.cas.cz/fgu/aip).

\section{Statistics}

Five outliers for glucose and two for ALT were eliminated and HDL-C, triglyceride, $\mathrm{FER}_{\mathrm{HDL}}$, ALT and BMI levels were log transformed to normalize their positively skewed distribution. Qualitative variables were analyzed using $\chi^{2}$, with Fisher exact test where appropriate and quantitative variables were analyzed by ANOVA (proc GLM). Major determinants of AIP and FER $_{\text {HDL }}$ were assessed applying multivariable linear regression analysis (Procedure REG in SAS). The analysis strategy was as following: (a) simple linear regression or ANOVA (for categorical variables) were used to identify variables associated with AIP or FER HDL $_{\text {}}$ at the level $\mathrm{P}<0.1$; (b) all the variables identified in the univariate analysis were inserted in a full multivariable linear regression model. To avoid collinearity problems, we checked for multicollinearity, measuring the variance inflation factor for each variable and the condition number for the full model. A variable whose variance inflation factor value is greater than 10 indicates the presence of collinearity; also, a large condition number, 100 or more, is an indication of the global instability of the regression coefficients. In our multivariate linear regression analyses on $\mathrm{FER}_{\mathrm{HDL}}$ we excluded LDL-C variable due to collinearity observed and we did not evaluate LDL-C in the AIP models because it was calculated with Friedewald formula from HDL-C and TG. Mean values are reported as mean \pm standard deviation or as geometric mean and $95 \%$ confidence interval for $\log$ transformed data. $\mathrm{P}$ value of less than 0.05 was considered to indicate statistical significance. All computations were carried out with the SAS statistical package (SAS System for Windows V8, SAS institute Inc. Cary, N.C.; SAS Institute Inc., 1989).

\section{Results}

Basic characteristics of the population are in the Table 1. Men significantly differed in almost all parameters from women, with more favourable risk pattern in women. There was no difference in presence of family history of premature CVD between males and females, and only few subjects suffered from CVD in both genders.

We observed positive relationship between number of risk factors and both FER $_{\mathrm{HDL}}$ and AIP values in both genders (Table 2).

\section{AIP determinants}

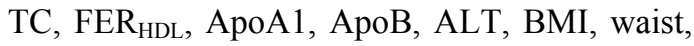
systolic blood pressure, diastolic blood pressure and smoking were all associated with AIP levels in both men and women in univariate analysis (Table 3). Glucose was significantly associated with AIP in women, but not in men. 
Table 1. Basic characteristics of the population.

\begin{tabular}{|c|c|c|c|}
\hline & $\operatorname{MEN}(n=208)$ & WOMEN (n=266) & $\mathbf{P}<$ \\
\hline$T C(\mathrm{mmol} / \mathrm{l})$ & $5.2 \pm 1.0$ & $5.0 \pm 0.9$ & 0.002 \\
\hline$L D L-C(\mathrm{mmol} / \mathrm{l})$ & $3.2 \pm 0.9$ & $2.9 \pm 0.7$ & 0.0001 \\
\hline$H D L-C(\mathrm{mmol} / \mathrm{ll})^{*}$ & $1.26(1.21-1.30)$ & $1.48(1.44-1.53)$ & 0.0001 \\
\hline$T G(\mathrm{mmol} / \mathrm{ll})^{*}$ & $1.46(1.35-1.57)$ & $1.05(0.98-1.12)$ & 0.0001 \\
\hline$A I P$ & $0.064 \pm 0.310$ & $-0.150 \pm 0.306$ & 0.0001 \\
\hline$F E R_{H D L} *$ & $14.01(13.21-14.84)$ & $10.61(10.08-11.17)$ & 0.0001 \\
\hline ApoA1 & $1.3 \pm 0.3$ & $1.4 \pm 0.3$ & 0.005 \\
\hline$A p o B$ & $0.9 \pm 0.2$ & $0.8 \pm 0.2$ & 0.0001 \\
\hline Glucose (mmol/l) & $5.1 \pm 0.6$ & $4.8 \pm 0.6$ & 0.001 \\
\hline$A L T^{*}$ & $0.44(0.42-0.47)$ & $0.27(0.25-0.28)$ & 0.0001 \\
\hline$B M I\left(k g / m^{2}\right) *$ & $26.1(25.6-26.7)$ & $24.1(23.6-24.6)$ & 0.0001 \\
\hline Waist $(\mathrm{cm})$ & $93.7 \pm 9.4$ & $80.4 \pm 11.6$ & 0.000 \\
\hline Systolic BP (mmHg) & $122 \pm 14$ & $116 \pm 15$ & 0.000 \\
\hline Diastolic BP ( $\mathrm{mmHg})$ & $79 \pm 9$ & $75 \pm 10$ & 0.000 \\
\hline Smoking & $74(35.75 \%)$ & $68(25.56 \%)$ & 0.020 \\
\hline CVD (CHD, MI, stroke, PVD) & $4(1.92 \%)$ & $3(1.13 \%)$ & NS \\
\hline Family history of CVD & $63(30.58 \%)$ & $83(31.20 \%)$ & NS \\
\hline
\end{tabular}

Data for continuous variables presented as mean \pm SD or * Geometric mean and $95 \%$ CI, TC - total cholesterol, TG - triglycerides, AIP - atherogenic index of plasma, ALT - alanine aminotransferase, BP - blood pressure, CVD - cardiovascular diseases

Table 2. Men and women stratified according to number of risk factors and their FER ${ }_{\text {HDL }}$ and AIP values.

\begin{tabular}{|c|c|c|c|c|c|c|}
\hline \multirow{2}{*}{$\begin{array}{l}\text { N. of risk } \\
\text { factors }\end{array}$} & \multirow{2}{*}{$\begin{array}{c}\text { MEN } \\
(n=208)\end{array}$} & \multirow{2}{*}{$\begin{array}{c}\text { FER }_{\text {HDL }} \\
\text { Geom. mean } \\
(95 \% \text { CI })\end{array}$} & \multirow{2}{*}{$\frac{\text { AIP }}{\operatorname{Mean} \pm \text { SD }}$} & \multirow{2}{*}{$\begin{array}{c}\text { WOMEN } \\
(n=266)\end{array}$} & \multirow{2}{*}{$\begin{array}{c}\text { FER }_{\text {HDL }} \\
\text { Geom. mean } \\
(95 \% \text { CI })\end{array}$} & \multirow{2}{*}{$\frac{\text { AIP }}{\text { Mean } \pm \text { SD }}$} \\
\hline & & & & & & \\
\hline 0 & $18(8.9 \%)$ & $8.91(7.38-10.76)$ & $-0.207 \pm 0.164$ & $45(17.3 \%)$ & $8.03(7.26-8.88)$ & $-0.334 \pm 0.209$ \\
\hline 1 & $68(33.7 \%)$ & $12.78(11.58-14.11)$ & $-0.0407 \pm 0.293$ & $97(37.3 \%)$ & $9.50(8.87-10.18)$ & $-0.232 \pm 0.241$ \\
\hline 2 & $66(32.7 \%)$ & $15.48(13.97-17.16)$ & $0.153 \pm 0.294$ & $70(26.9 \%)$ & $11.39(10.54-12.31)$ & $-0.097 \pm 0.285$ \\
\hline 3 & $33(16.3 \%)$ & $14.57(12.59-16.85)$ & $0.149 \pm 0.277$ & $35(13.5 \%)$ & $13.85(12.36-15.52)$ & $0.059 \pm 0.288$ \\
\hline 4 & $15(7.4 \%)$ & $18.20(14.81-22.37)$ & $0.227 \pm 0.234$ & $12(4.6 \%)$ & $17.80(14.62-21.67)$ & $0.170 \pm 0.299$ \\
\hline 5 & $2(1.0 \%)$ & $28.65(16.29-50.38)$ & $0.483 \pm 0.183$ & $1(0.4 \%)$ & $26.71(13.91-51.29)$ & $1.221(\mathrm{n}=1)$ \\
\hline$P$ & & $<0.0001$ & $<0.0001$ & & $<0.0001$ & $<0.0001$ \\
\hline
\end{tabular}

In multivariate analysis, in men, AIP levels were associated only with BMI, ApoA1, ApoB and smoking (Table 3). In women, AIP was associated with BMI, ApoA1, ApoB, total cholesterol, ALT and systolic blood pressure. In this model (model 1) BMI participated on $20.8 \%$ out of $35 \%$ of total variability explained by the model in men and on $23.4 \%$ out of $43 \%$ in women, respectively (Table 3 ). As expected, when also FER $\mathrm{HDL}_{\mathrm{H}}$ was included in the analyses (model 2), the $\mathrm{FER}_{\mathrm{HDL}}$ explained almost all of the variability observed (Table 3 ), both in men (52\%) and women (54\%).

$F E R_{H D L}$ determinants

In univariate analyses all the parameters except of FTO genotype and diastolic BP in women and glucose, ALT, FTO and MLX genotypes in men were significant determinants of FER $_{\mathrm{HDL}}$ (Tables 3 and 4). In multivariate analysis (Table 3 ), in men, FER $_{\mathrm{HDL}}$ levels were associated with HDL-C, TG, TC and waist in model 1. In women, it was, associated with HDL-C, TG, TC, apoB and ALT. 
Table 3. Univariate and multivariate linear regression analysis of metabolic, anthropometric, and genetic correlates of AIP and FER $\mathrm{HDL}_{\text {in }}$ men and women.

\begin{tabular}{|c|c|c|c|c|c|c|c|c|c|c|}
\hline \multirow[t]{3}{*}{ AIP } & \multicolumn{5}{|l|}{ MEN } & \multicolumn{5}{|l|}{ WOMEN } \\
\hline & Univariate & Model 1* & $\begin{array}{c}\text { Total } \\
\mathrm{R}^{2}=\mathbf{0 . 3 5 3 2}\end{array}$ & Model $2^{\#}$ & $\begin{array}{c}\text { Total } \\
\mathbf{R}^{2}=\mathbf{0 . 5 9 2 3}\end{array}$ & Univariate & Model 1* & $\begin{array}{c}\text { Total } \\
\mathrm{R}^{2}=\mathbf{0 . 4 3 3 2}\end{array}$ & Model $2^{\#}$ & $\begin{array}{c}\text { Total } \\
\mathrm{R}^{2}=\mathbf{0 . 5 9 6 4}\end{array}$ \\
\hline & $\mathbf{p}$ & $\mathbf{p}$ & Partial $\mathbf{R}^{2}$ & $\mathbf{p}$ & Partial $R^{2}$ & $\mathbf{p}$ & $\mathbf{p}$ & Partial $\mathbf{R}^{2}$ & $\mathbf{p}$ & Partial $\mathbf{R}^{2}$ \\
\hline$T C$ & 0.0137 & - & & - & & $<0.0001$ & 0.0225 & 0.0159 & 0.0456 & 0.0088 \\
\hline $\log F E R_{H D L}$ & $<0.0001$ & NA & & $<0.0001$ & 0.5233 & $<0.0001$ & NA & & $<0.0001$ & 0.5403 \\
\hline$A p o B$ & 0.0014 & 0.0204 & 0.0199 & - & & $<0.0001$ & $<0.0001$ & 0.0628 & - & \\
\hline ApoA1 & $<0.0001$ & $<0.0001$ & 0.0708 & 0.0389 & 0.0103 & 0.0001 & $<0.0001$ & 0.0745 & - & \\
\hline Glucose & 0.2674 & NA & & NA & & 0.0040 & - & & - & \\
\hline $\log A L T$ & 0.0330 & - & & 0.0199 & 0.0128 & 0.0895 & 0.0367 & 0.0136 & 0.0220 & 0.0114 \\
\hline $\log B M I$ & $<0.0001$ & $<0.0001$ & 0.2087 & 0.0054 & 0.0196 & $<0.0001$ & $<0.0001$ & 0.2339 & 0.0016 & 0.0227 \\
\hline Waist & $<0.0001$ & - & & 0.0439 & 0.0094 & $<0.0001$ & - & & - & \\
\hline Systolic BP & 0.0053 & - & & - & & 0.0063 & 0.0184 & 0.0176 & - & \\
\hline Diastolic BP & 0.0016 & - & & - & & 0.0172 & - & & - & \\
\hline Smoking & 0.0037 & 0.0030 & 0.0338 & 0.0212 & 0.0130 & 0.0756 & - & & - & \\
\hline CILP & 0.2141 & NA & & NA & & 0.0825 & - & & - & \\
\hline FTO & 0.1375 & NA & & NA & & 0.5286 & NA & & NA & \\
\hline$M L X$ & 0.9282 & NA & & NA & & 0.3768 & NA & & NA & \\
\hline \multirow[t]{3}{*}{$\operatorname{logFER} R_{H D L}$} & MEN & \multicolumn{9}{|c|}{ WOMEN } \\
\hline & Univariate & Model 1 ${ }^{\&}$ & $\begin{array}{c}\text { total } \\
\mathrm{R}^{2}=0.6646\end{array}$ & Model 2 & $\begin{array}{c}\text { total } \\
\mathrm{R}^{2}=0.6534\end{array}$ & Univariate & Model 1 ${ }^{\&}$ & $\begin{array}{c}\text { total } \\
R^{2}=0.6765\end{array}$ & Model $2^{\$}$ & $\begin{array}{c}\text { total } \\
R^{2}=0.6634\end{array}$ \\
\hline & $\mathbf{p}$ & $\mathbf{p}$ & Partial $\mathbf{R}^{2}$ & $\mathbf{p}$ & Partial $R^{2}$ & $\mathbf{p}$ & $\mathbf{p}$ & Partial $\mathbf{R}^{2}$ & $\mathbf{p}$ & Partial $\mathbf{R}^{2}$ \\
\hline$T C$ & 0.0015 & $<0.0001$ & 0.0599 & - & & $<0.0001$ & $<0.0001$ & 0.0400 & - & \\
\hline $\log H D L$ & $<0.0001$ & $<0.0001$ & 0.1397 & NA & & $<0.0001$ & $<0.0001$ & 0.4235 & NA & \\
\hline $\log T G$ & $<0.0001$ & $<0.0001$ & 0.4317 & NA & & $<0.0001$ & $<0.0001$ & 0.1702 & NA & \\
\hline$A I P$ & $<0.0001$ & NA & & $<0.0001$ & 0.5509 & $<0.0001$ & NA & & $<0.0001$ & 0.5589 \\
\hline ApoA1 & $<0.0001$ & - & & 0.0017 & 0.0232 & $<0.0001$ & - & & 0.0006 & 0.0268 \\
\hline$A p o B$ & $<0.0001$ & - & & 0.0108 & 0.0160 & $<0.0001$ & 0.0025 & 0.0169 & $<0.0001$ & 0.0589 \\
\hline Glucose & 0.76 & NA & & NA & & 0.008 & - & & - & \\
\hline $\log A L T$ & 0.26 & NA & & NA & & 0.003 & 0.0176 & 0.0110 & 0.0500 & 0.0073 \\
\hline $\log B M I$ & $<0.0001$ & - & & - & & $<0.0001$ & - & & - & \\
\hline Waist & $<0.0001$ & 0.0049 & 0.0179 & $<0.0001$ & 0.0460 & $<0.0001$ & - & & - & \\
\hline Systolic BP & 0.01 & - & & - & & 0.02 & - & & - & \\
\hline Diastolic BP & 0.01 & - & & - & & 0.08 & - & & - & \\
\hline Smoking & 0.03 & - & & - & & 0.03 & - & & - & \\
\hline CILP & 0.0007 & - & & 0.0329 & 0.0103 & 0.02 & - & & - & \\
\hline FTO & 0.17 & NA & & NA & & 0.83 & NA & & NA & \\
\hline$M L X$ & 0.87 & NA & & NA & & 0.04 & - & & - & \\
\hline
\end{tabular}

NA - variables not included in multivariable analysis due to $p>0.1$ in univariate or when only in one of the models used (AIP and logFER $\left.{ }_{H D L}\right), R^{2}$ the coefficient of determination, ${ }^{*}$ model 1 - multivariate analysis without logFER $R_{H D L}{ }^{*}$ model 2 - multivariate analysis with $\operatorname{logFER} R_{H D L}{ }^{\&}$ model 1 - multivariate analysis without $A I P,{ }^{\$}$ model 2 - multivariate analysis with $A I P$

TC - total cholesterol, TG - triglycerides, AIP - atherogenic index of plasma, ALT - alanine aminotransferase, BP - blood pressure, CILP

- rs16996148 CILP2 polymorphism, FTO - rs17817449 FTO polymorphism, MLX - rs3812316 MLXIPL polymorphism 
Table 4. Mean levels of FER ${ }_{\text {HDL }}$ and AIP according to genotypes.

\begin{tabular}{|c|c|c|c|c|}
\hline & \multicolumn{2}{|c|}{ FER $_{\text {HDL }}$ * } & \multicolumn{2}{|c|}{ AIP } \\
\hline & $\begin{array}{c}\text { MEN } \\
\text { Geom. mean }(95 \% \text { CI) }\end{array}$ & $\begin{array}{c}\text { WOMEN } \\
\text { Geom. mean }(95 \% \text { CI })\end{array}$ & $\begin{array}{c}\text { MEN } \\
\text { Mean } \pm \text { SD }\end{array}$ & $\begin{array}{r}\text { WOMEN } \\
\text { Mean } \pm \text { SD }\end{array}$ \\
\hline \multicolumn{5}{|l|}{ CILP } \\
\hline 11 & $14.98(14.04-15.98)$ & $10.84(10.27-11.44)$ & $0.091 \pm 0.302$ & $-0.152 \pm 0.292$ \\
\hline 12 & $14.10(12.07-16.47)$ & $8.74(7.59-10.07)$ & $0.091 \pm 0.315$ & $-0.280 \pm 0.291$ \\
\hline 22 & $6.15(3.93-9.63)$ & $8.99(4.31-18.73)$ & $-0.220 \pm 0.045$ & $-0.053 \pm 0.075$ \\
\hline$p$ & 0.0007 & 0.02 & 0.21 & 0.0825 \\
\hline p-rec & 0.0002 & 0.68 & 0.079 & 0.58 \\
\hline p-dom & 0.078 & 0.005 & 0.62 & 0.0492 \\
\hline \multicolumn{5}{|l|}{ FTO } \\
\hline 11 & $13.72(12.25-15.36)$ & $10.89(9.94-11.93)$ & $0.054 \pm 0.338$ & $-0.120 \pm 0.319$ \\
\hline 12 & $13.64(12.46-14.94$ & $10.51(9.75-11.33)$ & $0.039 \pm 0.303$ & $-0.168 \pm 0.291$ \\
\hline 22 & $15.81(13.83-18.08)$ & $10.57(9.54-11.71)$ & $0.152 \pm 0.283$ & $-0.168 \pm 0.322$ \\
\hline$p$ & 0.17 & 0.83 & 0.14 & 0.53 \\
\hline p-rec & 0.061 & 0.88 & 0.048 & 0.68 \\
\hline -dom & 0.56 & 0.55 & 0.66 & 0.26 \\
\hline \multicolumn{5}{|l|}{$M L X$} \\
\hline 11 & $14.35(13.36-15.42)$ & $10.96(10.34-11.61)$ & $0.075 \pm 0.301$ & $-0.142 \pm 0.312$ \\
\hline 12 & $13.85(12.02-15.96)$ & $9.29(8.31-10.38)$ & $0.076 \pm 0.337$ & $-0.211 \pm 0.312$ \\
\hline 22 & $16.21(6.92-37.98)$ & $10.98(7.78-15.49)$ & $0.145 \pm 0.260$ & $-0.139 \pm 0.208$ \\
\hline$p$ & 0.87 & 0.037 & 0.93 & 0.38 \\
\hline p-rec & 0.77 & 0.83 & 0.70 & 0.90 \\
\hline$p$-dom & 0.70 & 0.016 & 0.92 & 0.19 \\
\hline
\end{tabular}

* $\mathrm{p}$ values are from log transformed FER $\mathrm{HDL}_{\text {L }}$ analyses, $\mathrm{p}$-rec $-\mathrm{p}$ value for a model of recessive effect, $\mathrm{p}$-dom $-\mathrm{p}$ value for a model of dominant effect, CILP - rs16996148 CILP2 polymorphism, FTO - rs17817449 FTO polymorphism, MLX - rs3812316 MLXIPL polymorphism

However, in contrast to men, where TG levels explained 43 percent of the $\mathrm{FER}_{\mathrm{HDL}}$ variability, in women HDL-C was the major determinant ( $42 \%)$. When AIP levels were considered instead of HDL-C and TG in model 2, in both sexes, AIP levels explained more than $55 \%$ out of more than $65 \%$ of total $\mathrm{FER}_{\mathrm{HDL}}$ variability explained by models 2 .

CILP, FTO and MLX polymorphisms' relation with AIP and $F E R_{H D L}$

We did not find any significant association of genotypes of the three polymorphisms with AIP (Table 3 and 4). When we considered also recessive and dominant effect of the polymorphisms (Table 4), recessive model of FTO in males and dominant model of CILP in females were significantly related to AIP in univariate (Table 4) but not in multivariate analysis (data not shown).

In univariate analyses, CILP genotype in both men and women, recessive model of CILP in men and dominant models of CILP and $M L X$ in women were associated with FER $_{\mathrm{HDL}}$ levels (Table 4). However, CILP genotype remained a significant predictor of $\mathrm{FER}_{\mathrm{HDL}}$ in multivariate analysis only in men (in model 2) but not in women (Table 3). In the same line with this finding were highly significant associations of recessive effect of CILP on $\mathrm{FER}_{\mathrm{HDL}}$ in both model $1 \quad(\mathrm{p}=0.0007$, partial $\left.\mathrm{R}^{2}=0.0256\right)$ and model $2\left(\mathrm{p}=0.0004\right.$, partial $\left.\mathrm{R}^{2}=0.0303\right)$ in men. Dominant models of $C I L P$ and $M L X$ in women did not remain significant predictors of $F E R_{\mathrm{HDL}}$ levels in multivariate analysis (data not shown). 


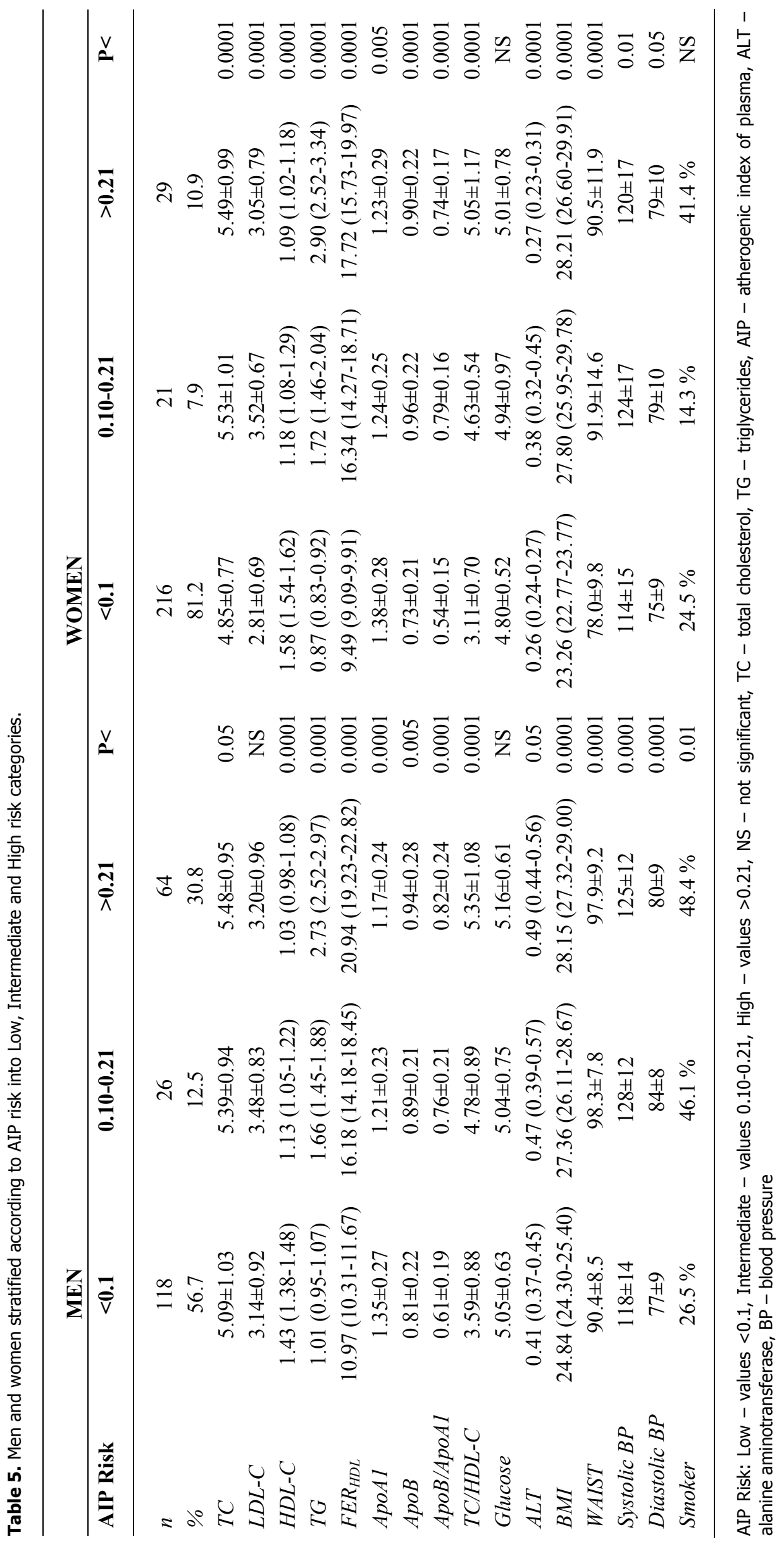


Men and women stratified according to AIP risk into low, medium and high risk categories

The data of men and women stratified according to the severity of AIP risk (Table 5) corresponded with criteria established for the assessment of the cardiovascular risk. Higher AIP risk was associated with significantly increased levels of $\mathrm{FER}_{\mathrm{HDL}}$, lipid and lipoprotein parameters, but also BMI, waist circumference, blood pressure, and number of smokers, the latter in men only. Different distribution of AIP risk was found in men and women; $81 \%$ of women while only $57 \%$ of men belonged to low risk category, and $31 \%$ of men and only $11 \%$ of women came to the group of the highest AIP risk (Table 5).

\section{Discussion}

In this study a relation between the novel biomarkers of cardiovascular diseases FER $_{\mathrm{HDL}}$ and AIP and conventional risk factors was assessed in 40 years old subjects of the general Slovak population. We also evaluated components of variability of FER $\mathrm{HDL}_{\mathrm{HD}}$ and AIP and association of three recently identified polymorphisms related to them, blood lipids and BMI.

Univariate analyses demonstrated that both, FER $_{\text {HDL }}$ and AIP, which strongly correlated with each other, are determined not only by lipoprotein parameters comprised of plasma lipids, apoAI and apoB but also by BMI, blood pressure and smoking. Moreover, also by glycaemia and ALT, in women. AIP levels were positively associated by half of total variability with BMI (cca $20 \%$ out of $40 \%$ ) if FER $_{\mathrm{HDL}}$ (as the marker of lipoprotein quality) was not included in the multivariate analyses. However, if FER $\mathrm{HDL}_{\mathrm{L}}$ was included in the model it explained almost all of the AIP variability observed (cca $53 \%$ ). The major determinant of FER $\mathrm{HDL}_{\text {was }}$ AIP explaining most of the $\mathrm{FER}_{\mathrm{HDL}}$ variability in the model. However, when TG and HDL-C levels were considered instead of AIP (Table 3), TG levels explained 43 percent (HDL-C $14 \%$ ) of the FER $_{\mathrm{HDL}}$ variability in men while in women HDL-C was the major determinant (42\%) compared to $17 \%$ of TG. The high impact of BMI on AIP variability and low impact of total cholesterol on variability of both biomarkers suggest their relatively independent role in the assessment of CVD risk.

Fasting levels of TG and HDL-C are well established risk factors for CVD and elevated TG levels together with low HDL-C levels are characteristic components of the atherogenic dyslipidemia (Grundy
1995). However, combining the contradictory parameters into one AIP $[\log (\mathrm{TG} / \mathrm{HDL}-\mathrm{C})]$ has shown to be significantly better in subjects with risk factors for CVD including male gender (Dobiášová and Frohlich 2001). Measurement of HDL-C concentration refers to the mass of cholesterol within high-density lipoproteins but this does not reflect the number of HDL-C particles and does not provide functional information (Genest 2008). On the other hand FER $_{\mathrm{HDL}}$ and AIP as markers of HDL-C, LDL-C and VLDL particle sizes (Dobiášová et al. 2011) might serve as a functional test of lipoprotein quality. We have analyzed data separately in men and women and have shown that the unified age of forty years in our population (as pre-menopausal status in women) even more strengthened the differences in the cardiovascular risk markers between genders. Eighty one percent of women in the study have been stratified into the category of the lowest risk according to AIP (Table 5) while only $11 \%$ into the high risk one. On the other hand, men belonged by 31 per cent to the high risk category and 57 per cent to the low one. Similar distributions were reported for men and women of control groups of survivors of myocardial infarction (Dobiášová et al. 2001). When pooled data of both men and women were analyzed in the regression models, gender was a significant determinant of AIP, but not of FER $\mathrm{HDL}_{\text {(data }}$ not shown). With the increase of AIP risk category gradually increased also markers of atherogenic lipoprotein profile, especially $\mathrm{FER}_{\mathrm{HDL}}$ and apoB levels (especially in men) contrary to LDL-C (Table 5). We have also shown the close relation of FER $\mathrm{HDL}_{\mathrm{HL}}$ and AIP to overweight and glycemia in women (Table 3) - markers of metabolic syndrome. Both markers were also able to reflect the delicate metabolic differences such as life-style between families of survivors of myocardial infarction and their controls (Dobiášová et al. 2001). The role of $\mathrm{FER}_{\mathrm{HDL}}$ and AIP as markers of insulin resistance was earlier reported (Tan et al. 1998). Also the ratio of the plasma concentrations of triglyceride to high-density lipoprotein cholesterol was proposed to be the best predictor of insulin resistance and LDL particle diameter (McLaughlin et al. 2005). It has been shown that this ratio independently predicted all-cause mortality in women (Bittner et al. 2009). However, Tan et al. (2004) demonstrated by using normal probability plots and correlations between residual error and expected residual error terms that AIP is preferable to the TG/HDL ratio for use in statistical analysis.

We have found that the CILP polymorphism was 
under a general effects model associated with FER $_{\mathrm{HDL}}$ in both sexes and this association remained significant after adjustment for other variables related to $\mathrm{FER}_{\mathrm{HDL}}$ in men. We have also demonstrated a highly statistically significant association of the minor allele with lower FER $_{\text {HDL }}$ under a recessive model of inheritance in men even after adjustment for other variables. However, we did not find significant association between CILP polymorphism and AIP though AIP levels were distributed according to CILP genotypes in a pattern similar to $\mathrm{FER}_{\mathrm{HDL}}$. Relatively smaller sample size might play a role in this finding. On the other hand, even despite a high correlation between AIP and FER HDL, this correlation is not absolute and we cannot exclude a real

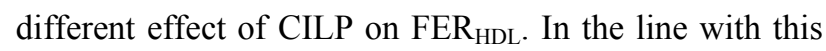
finding, with exception of dominant model of inheritance in women on TG levels ( $p=0.037$, univariate analysis), neither general, recessive nor dominant model of inheritance of the CILP polymorphism was associated with TG or HDL-C levels (data not shown). Only scant and inconsistent information exists so far on association of this polymorphism and blood lipids. Associations with LDL-C, HDL-C and TG were observed in some, but not all studies (Kathiresan et al. 2008, Tai et al. 2009, Nakayama et al. 2009). Although we did not find an association with AIP, our novel observation of statistically significant association of the minor allele with FER $_{\text {HDL }}$ under a recessive model of inheritance is consistent with the finding of recessive effect of the minor allele on HDL-C levels recently published by Tai et al. (2009). However, the exact role of the SNP or related SNPs on lipid metabolism still needs to be investigated.

In conclusions, FER $_{\mathrm{HDL}}$ and AIP related to the known markers of cardiovascular risk provide means to express their subtle interactions by one number. AIP as can be readily calculated from the routine lipid profile offers a simple marker of the risk and possible control of effectiveness of the therapy in clinical practice. Our novel finding of association between CILP polymorphism and FER $_{\text {HDL }}$ supports its role in lipid metabolism.

\section{Conflict of Interest}

There is no conflict of interest.

\section{Acknowledgements}

The study was supported by the Grant from Slovak Ministry of Health, 2003, the grants from Slovak Association of Atherosclerosis and Srdce rodiny foundation. A portion of this study was supported by the Grant NR/8328-3 from Ministry of Health of the Czech Republic, Project No 00023001 (IKEM). JAH is supported by project No. 1M0510.

\section{References}

AUSTIN MA, BRUNZELL JD, FITCH WL, KRAUSS RM: Inheritance of low density lipoprotein subclass patterns in familial combined hyperlipidemia. Arteriosclerosis 10: 520-530, 1990.

BITTNER V, JOHNSON BD, ZINEH I, ROGERS WJ, VIDO D, MARROQUIN OC, BAIREY-MERZ CN, SOPKO G: The triglyceride/high-density lipoprotein cholesterol ratio predicts all-cause mortality in women with suspected myocardial ischemia: a report from the Women's Ischemia Syndrome Evaluation (WISE). Am Heart J 157: 548-555, 2009.

BROWN BG, ZHAO XQ, CHAIT A, FISHER LD, CHEUNG MC, MORSE JS, DOWDY AA, MARINO EK, BOLSON EL, ALAUPOVIC P, FROHLICH J, ALBERS JJ: Simvastatin and niacin, antioxidant vitamins, or the combination for the prevention of coronary disease. $N$ Engl J Med 345: 1583-1592, 2001.

DAY IN, HUMPHRIES SE: Electrophoresis for genotyping: microtiter array diagonal gel electrophoresis on horizontal polyacrylamide gels, hydrolink, or agarose. Anal Biochem 222: 389-395, 1994.

DE BACKER G, AMBROSIONI E, BORCH-JOHNSEN K, BROTONS C, CIFKOVA R, DALLONGEVILLE J, EBRAHIM S, FAERGEMAN O, GRAHAM I, MANCIA G, CATS VM, ORTH-GOMÉR K, PERK J, PYÖRÄLÄ K, RODICIO JL, SANS S, SANSOY V, SECHTEM U, SILBER S, THOMSEN T, WOOD D; EUROPEAN SOCIETY OF CARDIOLOGY COMMITTEE FOR PRACTICE GUIDELINES: European guidelines on cardiovascular disease prevention in clinical practice: third joint task force of European and other societies on cardiovascular disease prevention in clinical practice. Eur J Cardiovasc Prev Rehabil 10: S1-S10, 2003. 
DOBIÁŠOVÁ M, FROHLICH J, ŠEDOVÁ M, CHEUNG MC, BROWN BG: Cholesterol esterification and atherogenic index of plasma correlate with lipoprotein size and findings on coronary angiography. $J$ Lipid Res 52: 566-571, 2011.

DOBIÁŠOVÁ M, FROHLICH J: The plasma parameter log (TG/HDL-C) as an atherogenic index: correlation with lipoprotein particle size and esterification rate in apoB-lipoprotein-depleted plasma (FERHDL). Clin Biochem 34: 583-588, 2001.

DOBIÁŠOVÁ M, FROHLICH J: Measurement of fractional esterification rate of cholesterol in plasma depleted of apoprotein B containing lipoprotein: methods and normal values. Physiol Res 45: 65-73, 1996.

DOBIÁŠOVÁ M, RAŠLOVÁ K, RAUCHOVÁ H, VOHNOUT B, PTÁČKOVÁ K, FROHLICH J: Atherogenic lipoprotein profile in families with and without history of early myocardial infarction; fractional esterification rate of cholesterol in plasma depleted of apoB lipoproteins $\left(\mathrm{FER}_{\mathrm{HDL}}\right)$ and logarithmically transformed ratio of triglycerides to HDL-cholesterol. Physiol Res 50: 1-8, 2001.

DOBIÁŠOVÁ M, URBANOVÁ Z, ŠAMÁNEK M: Relations between particle size of HDL and LDL lipoproteins and cholesterol esterification rate. Physiol Res 54: 159-165, 2005.

DOBIÁŠOVÁ M: Atherogenic index of plasma [log(triglycerides/HDL-cholesterol)]: theoretical and practical implications. Clin Chem 50: 1113-1115, 2004.

DREXEL H, AMAN FW, RENTSCH K, NEUNSCHWANDER C, LEUTHY A, KHAN SI, FOLLATH F: Relation of the level of high-density lipoprotein subfractions to the presence and extent of coronary artery disease. $A m J$ Cardiol 70: 436-440, 1992.

FROHLICH J, DOBIÁŠOVÁ M: Fractional esterification rate of cholesterol and ratio of triglycerides to HDLcholesterol are powerful predictors of positive findings on coronary angiography. Clin Chem 49: 1873-1880, 2003.

GAŠPAROVIČ J, BAŠISTOVÁ Z, FÁBRYOVÁ L, WSÓLOVÁ L, VOHNOUT B, RAŠLOVÁ K; SLOVAK MED PED FH GROUP: Familial defective apolipoprotein B-100 in Slovakia: Are differences in prevalence of familial defective apolipoprotein B-100 explained by ethnicity? Atherosclerosis 194: e95-e107, 2007.

GENEST J: The Yin and Yang of high-density lipoprotein cholesterol. J Am Coll Cardiol 51: 643-644, 2008.

GOESSLING W, MASSARO JM, VASAN RS, D'AGOSTINO RB Sr, ELLISON RC, FOX CS: Aminotransferase levels and 20-year risk of metabolic syndrome, diabetes, and cardiovascular disease. Gastroenterology 135: 1935-1944, 2008.

GRUNDY SM: Atherogenic dyslipidemia: lipoprotein abnormalities and implications for therapy. Am J Cardiol $\mathbf{7 5}$ (Suppl): 45B-52B, 1995.

HUBÁČEK JA, PIŤHA J, ADAMKOVA V, LANSKA V, POLEDNE R: A common variant in the FTO gene is associated with body mass index in males and postmenopausal females but not in premenopausal females. Czech post-MONICA and 3PMFs studies. Clin Chem Lab Med 47: 387-390, 2009.

KATHIRESAN S, MELANDER O, GUIDUCCI C, SURTI A, BURTT NP, RIEDER MJ, COOPER GM, ROOS C, VOIGHT BF, HAVULINNA AS, WAHLSTRAND B, HEDNER T, CORELLA D, TAI ES, ORDOVAS JM, BERGLUND G, VARTIAINEN E, JOUSILAHTI P, HEDBLAD B, TASKINEN MR, NEWTON-CHEH C, SALOMAA V, PELTONEN L, GROOP L, ALTSHULER DM, ORHO-MELANDER M: Six new loci associated with blood low-density lipoprotein cholesterol, high-density lipoprotein cholesterol or triglycerides in humans. Nat Genet 40: 189-197, 2008.

MCLAUGHLIN T, REAVEN G, ABBASI F, LAMENDOLA C, SAAD M, WATERS D, SIMON J, KRAUSS RM: Is there a simple way to identify insulin-resistant individuals at increased risk of cardiovascular disease? $\mathrm{Am} \mathrm{J}$ Cardiol 96: 399-404, 2005.

MÜLLER-NORDHORN J, BINTING S, ROLL S, WILLICH SN: An update on regional variation in cardiovascular mortality within Europe. Eur Heart J 29: 1316-1326, 2008.

NAKAYAMA K, BAYASGALAN T, YAMANAKA K, KUMADA M, GOTOH T, UTSUMI N, YANAGISAWA Y, OKAYAMA M, KAJII E, ISHIBASHI S, IWAMOTO S; JICHI COMMUNITY GENETICS TEAM (JCOG): Large scale replication analysis of loci associated with lipid concentrations in a Japanese population. $J$ Med Genet 46: 370-374, 2009. 
SCUTERI A, SANNA S, CHEN WM, UDA M, ALBAI G, STRAIT J, NAJJAR S, NAGARAJA R, ORRÚ M, USALA G, DEI M, LAI S, MASCHIO A, BUSONERO F, MULAS A, EHRET GB, FINK AA, WEDER AB, COOPER RS, GALAN P, CHAKRAVARTI A, SCHLESSINGER D, CAO A, LAKATTA E, ABECASIS GR: Genome-wide association scan shows genetic variants in the FTO gene are associated with obesity-related traits. PLoS Genet 3: e115, 2007.

TAI ES, SIM XL, ONG TH, WONG TY, SAW SM, AUNG T, KATHIRESAN S, ORHO-MELANDER M, ORDOVAS JM, TAN JT, SEIELSTAD M: Polymorphisms at newly identified lipid-associated loci are associated with blood lipids and cardiovascular disease in an Asian Malay population. J Lipid Res 50: 514-520, 2009.

TAN MH, JOHNS D, GLAZER NB: Pioglitazone reduces atherogenic index of plasma in patients with type 2 diabetes. Clin Chem 50: 1184-1188, 2004.

TAN MH, LOH KC, DOBIASOVA M, FROHLICH JJ: Fractional esterification rate of HDL particles in patients with type 2 diabetes. Relation to coronary heart disease risk factors. Diabetes Care 21: 139-142, 1998.

VRÁBLIK M, ČEŠKA R, ADAMKOVA V, PEASEY A, PIKHART H, KUBINOVA R, MARMOT M, BOBAK M, HUBACEK JA: MLXIPL variant in individuals with low and high triglyceridemia in white population in Central Europe. Hum Genet 124: 553-555, 2008.

YILMAZ Y: Liver function tests: Association with cardiovascular outcomes. World J Hepatol 2: 143-145, 2010.

www.biomed.cas.cz/fgu/aip AIP calculator 